\title{
Primary nasal meningioma- a case report
}

\section{Ghosh $\mathrm{A}^{1}$, Ghartimagar $\mathrm{G}^{1}$, Thapa $\mathrm{S}^{1}$,Shrestha $\mathrm{MK}^{2}$, Talwar $\mathrm{OP}^{1}$}

\author{
${ }^{1}$ Department of Pathology, Manipal Teaching Hospital, Pokhara, Nepal.
}

${ }^{2}$ Department of Radiology, Gandaki Medical College, Pokhara, Nepal.

\section{Keywords:}

Epistaxis;

Extracranial Meningioma;

Meningothelial;

Sinonasal.

\begin{abstract}
Extracranial meningiomas may be subdivided into primary (PEM) and secondary types based on absence or presence of intracranial attachments respectively. Primary sinonasal tract meningiomas are rare with unknown etiopathology and non-specific clinical presentation. Of these PEMs, only $11.5 \%$ are in the nasal cavity and nasal septum. To our knowledge less than 50 cases of PEM of nasal cavity have been reported in the literature. We report a case of a 22 years old male who presented with epistaxis and increasing nasal stuffiness for the last one year.
\end{abstract}

\section{INTRODUCTION}

Meningioma is a common tumor accounting for $15 \%$ of all intracranial tumors. ${ }^{1}$ Extracranial meningiomas (EM) are rare comprising less than $2 \%$ of all meningiomas and sites such as spine, nasal septum, neck, chest, shoulder, peritoneum have been reported. ${ }^{1,2}$ Extracranial meningiomas may be subdivided into primary (PEM) and secondary types based on absence or presence of intracranial attachments respectively. Of these PEMs, only $11.5 \%$ are in the nasal cavity and nasal septum. To our knowledge less than 50 cases of PEM of nasal cavity have been reported in the literature. $^{2}$

\section{CASE REPORT}

A 22 years old male presented in the emergency with continuous nasal bleeding from left nostril for 10 hours. He

\footnotetext{
Correspondence:

Dr. Arnab Ghosh, MBBS, MD

Professor, Department of Pathology

Manipal College of Medical Sciences, Pokhara, Nepal

Email:docarnab2k@yahoo.com
}

had occasional episodes of epistaxis and increasing nasal stuffiness for the last one year. There was no history of trauma and bleeding from any other site. On enquiry, patient revealed past history of surgery of nasal mass in left nasal cavity 10 years back in other center which was diagnosed as oxyphilic adenoma at that time. On examination with rhinoscope, a bleeding nasal mass was seen filling the left nostril. General examination as well as routine blood tests, biochemical profiles and coagulation tests were within normal limit.

On CT scan, a minimally enhancing soft tissue solid mass measuring $5 \mathrm{~cm}$ was seen attached to left side of nasal septum filling left middle meatus (fig.1). No bony erosion was noted. A presumptive clinico-radiological diagnosis of anterochoanal polyp was made. Endoscopic excision of the nasal mass was done. On microscopic examination, meningothelial cells were seen arranged in nests and sheets (fig.2,3). Occasional intranuclear inclusion (fig.3 inset) and psammoma bodies were noted. No mitosis or tumor necrosis was seen. A histopathological diagnosis of sinonasal 


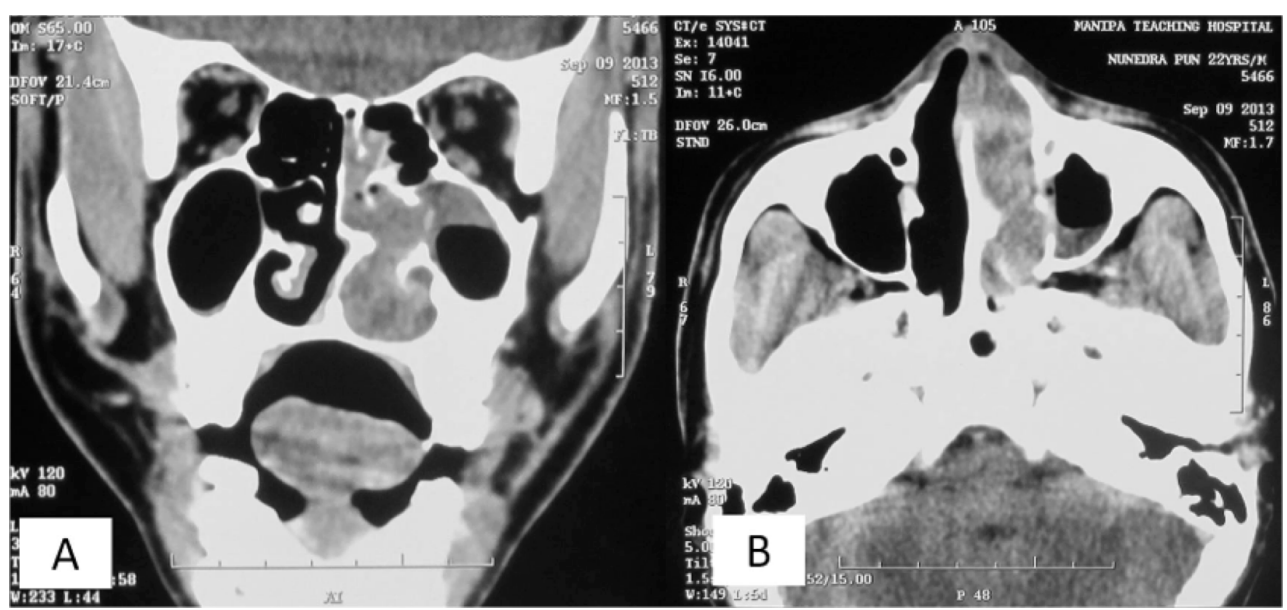

Figure 1: Plain non-contrast CT. (A) Coronal reformatted images and (B) Axial image, soft tissue window showing left soft tissue density in the nasal cavity inseparable from inferior turbinate and extending to middle ethmoidal air cells. Left maxillary sinus shows fluid level.

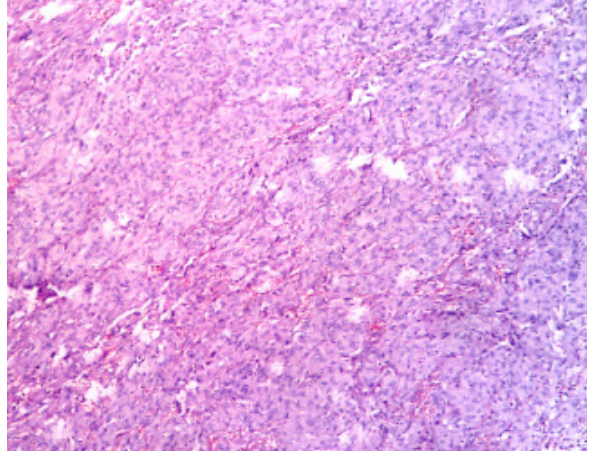

Figure 2: Photomicrograph showing meningothelial cells, (HE stain, x100).

meningothelial meningioma was given. Repeat CT scan did not show any intracranial involvement and confirmed the primary nature of the tumor. On postoperative follow up of 3 years, patient is doing well.

\section{DISCUSSION}

The origin of primary extracranial meningiomas is unclear. Several theories suggest that these lesions arise from arachnoid cells in nerve sheaths, ectopic arachnoid cells entrapped extra-cranially during neural tube closure and pleuripotent mesenchymal cells. ${ }^{3,4}$ In one series, mean age for nasal meningiomas was 28 with $40 \%$ being below 20 yrs of age. ${ }^{4}$ Among PEMs, females are more affected in petrous and sinonasal meningiomas, males are affected more in cutaneous meningiomas while for other sites there is no gender predilection. Our case, however, was a 22 year male with sinonasal meningioma. Clinically most patients present with non-specific symptoms including nasal stuffiness, episodes of epistaxis, hydrorrhea, hyposmia and headache. ${ }^{3,4}$ Under nasal endoscopy, usually it presents as pink to grey well circumscribed lobulated mass which may or may not bleed. On radiology, calcification and local invasion may mimic malignant tumor. ${ }^{5}$

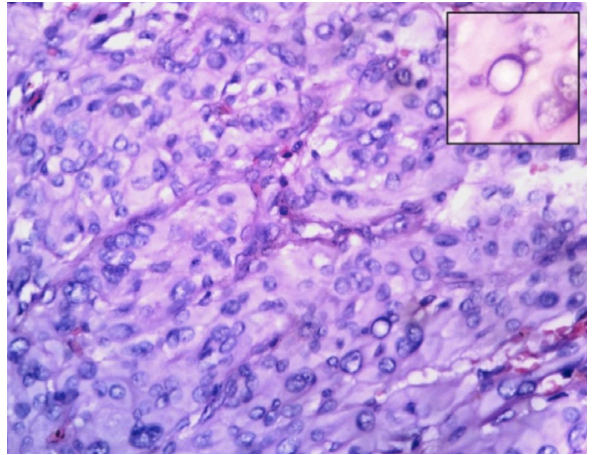

Figure 3: Photomicrograph showing high power view of meningothelial cells, (HE stain, x400). Inset showing nuclear inclusion.

Histological diagnosis may be difficult to establish because of their uncommon ectopic site and non specific clinicradiological appearance. ${ }^{1}$ The microscopic features are characteristic in meningothelial type but may be less typical in other histological forms. ${ }^{1,2}$ Histological differentials include carcinoma, melanoma, olfactory neuroblastoma and ossifying fibroma. ${ }^{6}$ Our case showed classical meningothelial pattern with presence of intranuclear inclusions and psammoma bodies and absence of mitosis, anaplasia and necrosis. Positivity to vimentin, EMA, S-100, keratin may be helpful in difficult cases. ${ }^{?}$

WHO classifies meningioma into 3 categories viz., grade I $(>80 \%)$ as benign meningioma, grade II (5-15\%) as atypical meningioma with frequent mitosis and grade III $(1-2 \%)$ as anaplastic type. ${ }^{8}$ Four major histological varieties include meningothelial, fibroblastic, transitional and angioblastic. The most common form is meningothelial meningioma as in our case.

Whenever surgery is possible, complete resection is the treatment of choice and if surgery is not possible, adjuvant radiotherapy is necessary to stabilize the lesion. ${ }^{1}$ Recurrence rate after surgery varies as widely as 7 to $84 \%$ in different 
series. $^{3}$ In our case, the patient is from nearby area and is on regular follow up. The slides with initial diagnosis of oxyphilic adenoma at the age of 12 years were reviewed which showed similar morphological picture. So the current presentation may be considered as recurrence. However intracranial extension was not found which is a good prognostic factor for the patient.

\section{CONCLUSION}

Primary sinonasal tract meningiomas are rare with unknown etiopathology and non specific clinical presentation. Confirmation of the diagnosis rests on histological examination. The prognosis is excellent after complete surgical removal without adjuvant therapy. Regular follow up is mandatory to rule out recurrence.

\section{REFERENCES}

1. Mnejja M, Hammami B, Bougacha L, Kolsi N, Mnif H, Chakroun A. Primary sinonasal meningioma. Eur Ann Otorhinolaryngol Head Neck Dis.2012;129:e47-e50. Crossref

2 Baek BJ, Shin JM,Lee CK, Lee JH, Lee KH. Atypical primary meningioma in the nasal septum with malignant transformation and distant metastasis. BMC Cancer 2012;12:275. Crossref
3. Rushing EJ, Bouffard JP, McCall S. Primary extracranial meningiomas: an analysis of 146 cases. Head Neck Pathol 2009;3:116-30. Crossref

4. Ho K-L. Primary meningioma of the nasal cavity and paranasal sinuses. Cancer 1980;46:1442-7. Crossref

5. Liesa RF, Esteban J, Obon JP. Méningiome primitive nasosinusien. Ann Otolaryngol Chir Cervicofac 1991;108:34-7.

6. Thompson LD, Gyure KA. Extracranial sinonasal tract meningiomas: a clinicopathologic study of 30 cases with a review of the literature. Am J Surg Pathol 2000;24:640-50. Crossref

7. Sharma JK, Pippal SK, Sethi Y. A rare case of primary nasoethmoidal meningioma. IJO-HNS 2006;58:101-3.

8. Perry A, Louis DN, Scheithauer BW, Budka H, von Diemling A, Meningiomas.In: Louis DN, Ohgaki H, Wiestler OD, Cavenee WK, editors. World Health Organization Classification of Tumours of the Central Nervous System. 4th ed. Lyon: IARC press; 2007. p.164-72. 